\title{
Laminated Free Standing PEDOT:PSS Electrode for Solution Processed Integrated Photocapacitors via Hydrogen-Bond Interaction
}

Yingzhi J in, Zaifang Li, Qin Leiqiang, Xianjie Liu, Lin Mao, Yazhong Wang, Fei Qin, Yanfeng Liu, Yinhua Zhou and Fengling Zhang

The self-archived postprint version of this journal article is available at Linköping University Institutional Repository (DiVA):

http:// urn.kb.se/ resolve?urn=urn:nbn:se:liu:diva-143906

N.B.: When citing this work, cite the original publication.

J in, Y., Li, Z., Leiqiang, Q., Liu, X., Mao, L., Wang, Y., Qin, F., Liu, Y., Zhou, Y., Zhang, F., (2017), Laminated Free Standing PEDOT:PSS Electrode for Solution Processed Integrated Photocapacitors via Hydrogen-Bond Interaction, ADVANCED MATERIALS INTERFACES, 4(23), .

https:// doi.org/ 10.1002/ admi.201700704

Original publication available at:

https://doi.org/10.1002/admi.201700704

Copyright: Wiley

http:// eu.wiley.com/WileyCDA/ 


\section{WILEY-VCH}

DOI: 10.1002/ ((please add manuscript number))

Article type: Full Paper

\section{Laminated free standing PEDOT:PSS electrode for solution processed integrated photo-} capacitors via hydrogen-bond interaction

Yingzhi Jin, Zaifang Li*, Leiqiang Qin, Xianjie Liu, Lin Mao, Yazhong Wang, Fei Qin, Yanfeng Liu, Yinhua Zhou and Fengling Zhang*

Y. Jin, Dr. Z. Li, Dr. L. Qin, Dr. X. Liu, Y. Wang, Y. Liu, Prof. F. Zhang

Department of Physics, Chemistry and Biology (IFM), Linköping University, SE-58183 Linköping, Sweden

E-mail: zaifang.li@liu.se,fenzh@ifm.liu.se.

F. Qin, L. Mao, Prof. Y. Zhou

Wuhan National Laboratory for Optoelectronics, and School of Optical and Electronic Information, Huazhong University of Science and Technology, Wuhan 430074, China

Prof. Y. Zhou

State Key Laboratory of Luminescent Materials and Devices, South China University of Technology, Guangzhou 510640, China 


\section{WILEY-VCH}

Keywords: Lamination method, Free standing PEDOT:PSS, Integrated photo-capacitor, Metalfree.

\section{Abstract}

In this work, a novel lamination method employing hydrogen-bond interaction to assemble a highly conductive free standing PEDOT:PSS film as a common electrode is demonstrated in a solution processed metal-free foldable integrated photo-capacitor (IPC) composed of a monolithic organic solar cell (OSC) and a capacitor. The highlights of the work are: (1) micron free standing PEDOT:PSS electrode is successfully laminated onto a relatively large area (1 $\mathrm{cm}^{2}$ ) OSCs; (2) a free standing capacitor based on the PEDOT:PSS electrode is achieved; (3) the IPC demonstrates an overall efficiency of $2 \%$ and an energy storage efficiency of $58 \%$, which is comparable with those of IPCs based on metallic common electrodes; (4) the novel lamination method for PEDOT:PSS electrode enables free standing PEDOT:PSS broad applications in solution processed flexible organic electronics, especially tandem or/and integrated organic electronic devices. Furthermore, the IPC is foldable with excellent cycling stability (No decay after 100 recycles at $1 \mathrm{~mA} \mathrm{~cm}^{-2}$ ). These results indicate that free standing PEDOT:PSS film is a promising candidate as common electrodes for IPCs to break the restrictions of metal electrodes. The demonstrated lamination method will greatly extend the applications of PEDOT:PSS electrodes to large area flexible organic electronic devices. 


\section{WILEY-VCH}

\section{Introduction}

An integrated photo-capacitor (IPC), combined a solar cell and a capacitor by sharing a common electrode to simultaneously realize optical energy harvesting and electrical energy storage, received tremendous attention because the fluctuating and intermittent solar irradiation cannot provide continuous steady reliable energy supply. ${ }^{[1]}$ In 2004, Murakami et al. firstly reported the in-situ energy harvesting and storage by integrating a dye-sensitized solar cell (DSSC) and capacitor. ${ }^{[2]}$ After that, different types of solar cells, such as DSSCs, ${ }^{[3]}$ organic solar cells (OSCs), ${ }^{[4]}$ quantum dots sensitized solar cells ${ }^{[5]}$ and perovskite solar cells ${ }^{[6]}$ have been integrated with capacitors for IPCs. At present, the most of IPCs are based on DSSCs and capacitors. However, the liquid electrolytes in most DSSCs are prone to leak and result in the failure of the devices. ${ }^{[7]}$ OSCs possess advantages over DSSCs for all-solid state devices, light-weight and good flexibility, which are considered to be promising alternatives. In 2010, Srinivasan et al. demonstrated an all-solid state IPC based on OSC and capacitor. ${ }^{[4]}$ However, the IPC demonstrated poor cycle stability. In 2014, Peng et al. fabricated a wire-shaped IPC in which both of the OSC and capacitor were integrated onto a Ti wire substrate. ${ }^{[8]}$ This IPC device showed a promising energy storage efficiency $\left(\eta_{\text {storage }}\right)$ of $65.6 \%$ and an overall efficiency ( $\eta_{\text {overall }}$ ) of $0.82 \%$. In 2015, IPC consisting of series connected OSCs and graphene capacitors was reported by Amaratunga et al. ${ }^{[9]}$ Recently, a high performance compact and monolithically stacked IPC by employing a novel electric glue and an efficient solar cell was reported by Lee’s group. ${ }^{[10]}$ Despite encouraging progress has been achieved with various IPCs, the development of IPCs is mostly limited by the poor capacitance and complex process of metal common electrodes. Therefore, exploring non-metallic highly electrical conductive and high capacitance common electrodes are urgently needed for enhancing both electron transport and storage capability of IPCs. 


\section{WILEY-VCH}

Conducting polymers, hold the advantage of light weight, excellent mechanical flexibility, high conductivity and solution processibility, have been under intensive research for application in electronic devices. ${ }^{[11]}$ Among them, poly(3,4-ethylenedioxythiophene):poly(styrenesulfonate) (PEDOT:PSS) has been widely used as electrodes to replace metals and indium tin oxide (ITO) in organic devices due to its excellent air and thermal stability, high transparency in the visible spectral region and high conductivity over $10^{3} \mathrm{~S} / \mathrm{cm} \cdot{ }^{[12]}$ Furthermore, good capacitance of PEDOT:PSS makes it an ideal candidate for common electrodes in IPCs. ${ }^{[13]}$ Thin PEDOT:PSS electrodes fabricated by spin coating, printing, or film transfer lamination ${ }^{[14]}$ have sheet resistance about $100 \Omega \mathrm{sq}^{-1},{ }^{[15]}$ which only meets the requirement of small area devices, but too large for large area organic electronic devices. ${ }^{[16]}$ Therefore, thick PEDOT:PSS films with small sheet resistances are urgently needed for large area high performance electronic devices. Recently, highly conductive thick free-standing PEDOT:PSS films were realized and utilized in capacitors and thermoelectrics. ${ }^{[17]}$ Nevertheless, employing such free standing thick PEDOT:PSS film as electrodes in OSCs has not been demonstrated, yet, due to the poor quality of thick PEDOT:PSS film and lacking suitable methods to assemble it with the active layers in OSCs.

Here we demonstrate a novel lamination method for utilizing free standing PEDOT:PSS electrode in IPC by employing a nonionic surfactant polyethylene glycol 2,5,8,11-tetramethyl6- dodecyne-5,8-diol ether (PEG-TmDD), which makes two PEDOT:PSS interfaces adhere tightly via strong hydrogen-bond interaction. To demonstrate the method, a solution processed foldable metal-free IPC consisting of a $1 \mathrm{~cm}^{2}$ OSC based on poly(3-hexylthiophene):indene$\mathrm{C}_{60}$ bis-adduct (P3HT:ICBA) and a free standing capacitor with a structure of PEDOT:PSS/ $\mathrm{H}_{3} \mathrm{PO}_{4}$-PVA/PEDOT:PSS via employing thick PEDOT:PSS film as a common electrode are fabricated and characterized. The $\eta_{\text {overall }}$ of the IPC is calculated to be around $2 \%$ and an energy storage efficiency of 58\%, which is comparable with previous report based on 


\section{WILEY-VCH}

metal electrodes. ${ }^{[10,18]}$ The foldable IPC also demonstrates excellent cycling stability (without decay after 100 recycles). Above results indicate that free standing PEDOT:PSS film has a great potential as non-metallic common electrodes for IPCs and other kinds of solution processed large area flexible organic electronic devices.

\section{Results and discussions}

\subsection{Characteristics of PEDOT:PSS films}

Spin-coated PEDOT:PSS top electrode with a film thickness of $226 \mathrm{~nm}$ (measured by DEKTAK 150) demonstrates a sheet resistance of $83.3 \Omega \mathrm{sq}^{-1}$ (measured by four point probe) and calculated electrical conductivity of $531 \mathrm{~S} \mathrm{~cm}^{-1}$ (Table S1). X-ray photoelectron spectroscopy (XPS) and ultraviolet photoelectron spectroscopy (UPS) measurements are employed to investigate the influence of ethylene glycol (EG) and PEG-TmDD on the PEDOT:PSS films. XPS measurement of sulfur atoms (showed in Figure S1a, b) shows the peak intensity at $168 \mathrm{eV}$ derived from PSS decreased slightly, which indicates the contents of PSS decreased from $62.5 \%$ to $57.8 \%$ after EG and PEG-TmDD treatment. Figure S1c demonstrates the carbon atom characteristics, from which we can find that a new peak around $286 \mathrm{eV}$ derived from $\mathrm{CH}_{2}-\mathrm{OH}$ bond is observed after doped. With adding 5\% EG and 0.2\% PEG-TmDD, the work function of the PEDOT:PSS film decreased slightly from 5.02 (pure) to $4.77 \mathrm{eV}$ (doped) as shown in Figure S2.

The detailed preparation of the free standing PEDOT:PSS film will be discussed in the experimental section. The Scanning Electron Microscope (SEM) image (shown in Figure 1a) of free standing PEDOT:PSS film exhibits an uniform surface. The inset of Figure 1a is the photo-image of free standing PEDOT:PSS film with a film thickness of $\sim 6 \mu \mathrm{m}$ and a low sheet resistance of $\sim 5 \Omega \mathrm{sq}^{-1}$ (Table S1), which meets the requirements of large area organic electronic devices. As the mechanical strength of the PEDOT:PSS film is a very important parameter, we 


\section{WILEY-VCH}

measured the conductance of the laminated layers (spin-coated and free standing PEDOT:PSS) via bending (Figure S3). The laminated layers enabled by hydrogen bonding exhibit good flexibility and excellent bonding effect even after 400 bending times.

\subsection{Characterizations of OSCs}

To know the effect of free standing PEDOT:PSS electrode on the performance of OSCs, two kinds of metal-free OSCs with the structure of ITO/PEI/P3HT:ICBA/PEDOT:PSS (Figure 1b) and active area of $1 \mathrm{~cm}^{2}$ are fabricated. One is using spin-coated PEDOT:PSS alone as a top electrode (Cell-1 as a reference device) and the other (Cell-2) laminating free standing PEDOT:PSS film on the top of Cell-1 assistant by hydrogen-bond interaction, which will be discussed systematically in the next part. Cell-1 demonstrate a moderate performance of opencircuit voltage $\left(V_{\text {oc }}\right)$ of $0.85 \mathrm{~V}$, short-circuit current density $\left(J_{\mathrm{sc}}\right)$ of $5.93 \mathrm{~mA} \mathrm{~cm}{ }^{-2}$, fill factor (FF) of 0.43 and power conversion efficiency (PCE) of 2.17\%. Encouragingly, Cell-2 with laminated free standing PEDOT:PSS electrode demonstrates an improved performance of PCE up to $3.44 \%$ with a $V_{\mathrm{oc}}=0.88 \mathrm{~V}, J_{\mathrm{sc}}=7.10 \mathrm{~mA} \mathrm{~cm}{ }^{-2}$ and $\mathrm{FF}=0.55$. The corresponding current density-voltage $(J-V)$ curves of two solar cells in dark and under illumination of AM 1.5 are presented in Figure 1c. The photovoltaic parameters are summarized in Table 1. The performance of Cell-2 is comparable with the PCE (3.84\%) of solar cells (Cell-3) using Ag as the top electrode (Table 1 and Figure S4). The series resistance $\left(R_{\mathrm{S}}\right)$ of the three solar cells are calculated and listed in Table 1, which show that Cell-2 holds much lower $R_{\mathrm{s}}$ of $16.7 \Omega$ than Cell-1 ( $\left.R_{\mathrm{S}} 46.7 \Omega\right)$. The improved PCE should be attributed to the enhanced electrical conducting of the top PEDOT:PSS electrode and thus a better charge collection and transport. ${ }^{[19]}$ To further understanding the effect of free standing PEDOT:PSS film on the enhancement of $J_{\mathrm{sc}}$ and $\mathrm{FF}$, the charge extraction properties is investigated by measuring the photocurrent density $\left(J_{\mathrm{ph}}\right)$ versus the effective voltage $\left(V_{\text {eff }}\right)$ of the solar cells. $J_{\mathrm{ph}}$ is determined by the equation $J_{\mathrm{ph}}=J_{\mathrm{L}}-J_{\mathrm{D}}$, where $J_{\mathrm{L}}$ and $J_{D}$ are the current densities under illumination and in dark, 


\section{WILEY-VCH}

respectively. $V_{\text {eff }}$ is determined by the equation $V_{\text {eff }}=V_{0}-V$, where $V_{0}$ is the voltage at $J_{\mathrm{ph}}=0$ and $V$ is applied voltage. Figure $1 \mathbf{d}$ shows the $J_{\mathrm{ph}}$ of two devices saturate at large $V_{\text {eff }}$ value, indicating that all of the photogenerated excitons are dissociated into free carriers and all carriers extracted by the electrodes. ${ }^{[20]}$ Moreover, The $J_{\text {ph }}$ at a small $V_{\text {eff }}$ in Cell-2 is higher than that of Cell-1, which suggests a higher charge extraction efficiency and resulting in a higher FF. ${ }^{[21]}$ In addition, we fabricated device with an effective area of $2.25 \mathrm{~cm}^{2}$. The performance are summarized in Table S2 and the $J$ - $V$ curve is shown in Figure S5, which also demonstrate decent performance. The decreased PCE (2.53\% for $\left.2.25 \mathrm{~cm}^{2}\right)$ mainly caused by small FF due to series resistance increase with increased effective area. ${ }^{[16]}$ The photovoltaic performance dependence on the thickness of electrode is investigated (Figure S6) and the corresponding parameters are summarized in Table S3, which shows that averaged device performance is gradually improved with the film thickness.

\subsection{The mechanism of free standing PEDOT:PSS lamination}

As we know, PSS molecules possess rich acidic sulfonic groups $\left(-\mathrm{SO}_{3} \mathrm{H}\right)$ and easily form $\mathrm{H}$ bonds with hydroxyl groups $(-\mathrm{OH}) .{ }^{[22]}$ In our previous work, we found that a non-ionic surfactant PEG-TmDD could decompose into EG and 2,5,8,11-tetramethyl-6- dodecyne-5,8diol ether (TmDD). ${ }^{[23]}$ The TmDD is a solid state compound at room temperature and possesses two hydroxyl groups (-OH) in each side, which could be employed as a strong adhesive for PEDOT:PSS film lamination. The corresponding procedures are presented in Figure 2. Firstly, a thin PEDOT:PSS film is spin-coated on the top of active layer (P3HT:ICBA) by using PH1000 solution doped with 5\% EG and 2\% PEG-TmDD. After thermal annealing at $120{ }^{\circ} \mathrm{C}$ for 5 minutes, many TmDD molecules will appear in the PEDOT:PSS film. At the meantime, the free standing PEDOT:PSS electrode is dipped into PH1000 solution doped with 5\% EG and 2\% PEG-TmDD for wetting. Then the wet free standing PEDOT:PSS film is put onto the top of the spin-coated PEDOT:PSS electrode followed by lamination in a vacuum (around $1 \mathrm{kPa}$ ) for 5 


\section{WILEY-VCH}

min. After that, the free standing PEDOT:PSS film is successfully adsorbed onto the spin-coated PEDOT:PSS layer assisted by the formation of hydrogen-bond interaction with the TmDD as the bridge. The contrast experiment without surfactant is performed under the same condition, which shows that the free standing PEDOT:PSS film cannot be laminated onto the spin-coated PEDTO:PSS electrode.

\subsection{Characterizations of free standing capacitor}

To further explore the potential of the free standing PEDOT:PSS electrodes for energy storage, a free standing solid-state capacitor is fabricated by employing $\mathrm{H}_{3} \mathrm{PO}_{4}-\mathrm{PVA}$ as electrolyte. The performance of the all-solid-state supercapacitor is investigated based on cyclic voltammetry (CV) curves. As shown in Figure 3a, the CV curves recorded at different scan rates, from which we can find that the CV curves remained nearly rectangle shape even the scan rate increased from 25 to $200 \mathrm{mV} \mathrm{S}^{-1}$. This result indicates the free standing PEDOT:PSS electrodes possess a low resistance and good reversibility. The galvanostatic charge-discharge (GCD) profiles with a voltage window of $0.8 \mathrm{~V}$ are shown in Figure $3 \mathbf{b}$. The near triangular shapes of these curves indicate good reversibility of the charging/discharging process, which is in good agreement with the CV curves shown in Figure 3a. The current density dependence of the specific areal capacitances $\left(C_{\mathrm{A}}\right)$ can be calculated from different current densities and the relative curves are demonstrated in Figure 3c. The capacitance of the device reaches high $C_{\mathrm{A}}$ of $30 \mathrm{mF} \mathrm{cm} \mathrm{c}^{-2}$ at a current density of $0.5 \mathrm{~mA} \mathrm{~cm}{ }^{-2}$. Furthermore, the capacitor shows superior rate performance. With a current density increase from 0.125 to10 $\mathrm{mA} \mathrm{cm}^{-2}$, this free standing capacitor retained approximately $81 \% C_{\mathrm{A}}$, indicating its outstanding charging/discharging rate stability. After 5000 cycles at a current density of $1 \mathrm{~mA} \mathrm{~cm}^{-2}$, over $80 \% C_{\mathrm{A}}$ is retained (Figure 3d), suggesting excellent cycle stability of the free standing capacitor. To show further the merits of the free standing film as the electrode material, the electrochemical impedance spectra (EIS) of devices are performed. Figure S7 exhibits the Nyquist plot in the frequency range from 0.01 to 100 


\section{WILEY-VCH}

$\mathrm{kHz}$. At the high frequency, the ignorable charge-transport semicircle indicating a low resistance of the device, which is consistent well with the CV and GCD characterizations. The key parameters of energy density $\left(E_{\mathrm{Ca}}\right)$ and power density $\left(P_{\mathrm{Ca}}\right)$ are calculated to be $2.57 \times 10^{-6}$ Wh cm $\mathrm{cm}^{-2}$ and $0.4 \mathrm{~mW} \mathrm{~cm}^{-2}$ at a current density of $1 \mathrm{~mA} \mathrm{~cm}{ }^{-2}$, respectively.

\subsection{Characterizations of the IPC}

For realizing simultaneous energy harvesting and storage in a single device, we fabricated IPC by integrating the Cell-2 and free standing capacitor by using free standing PEDOT:PSS film as common electrode. The structure of the IPC is illustrated in Figure 4a and the photo image under completely foldable condition is shown in Figure $\mathbf{4 b}$, from which we can find that the IPC possesses good foldable property due to the excellent flexibility of free standing PEDOT:PSS film. The photo-charging and discharging performance of the IPC is investigated under AM 1.5 simulated sunlight $\left(100 \mathrm{~mW} \mathrm{~cm}^{-2}\right)$ illumination. The OSC (Cell-2) with an effective area of $1 \mathrm{~cm}^{2}$ demonstrates a current density of $7 \mathrm{~mA} \mathrm{~cm}{ }^{-2}$ under AM 1.5. As shown in Figure 4c, the capacitor can be charged to $0.8 \mathrm{~V}$ in $5 \mathrm{~s}$, suggesting a good transport performance of the IPC. After that, the IPC is discharged at varies current density from 0.125 to $1 \mathrm{~mA} \mathrm{~cm}^{-2}$. For comparison, the auto-lab charging are employed with a same charging current of $7 \mathrm{~mA} \mathrm{~cm}^{-2}$ and discharge at the same current densities (Figure 4d). Interestingly, the discharge times driven by the OSC are slightly longer than those of pure capacitors driven by external power source, which could be caused by the introduced solar cell sub-device and the resulting delay effect of the voltage transient in the solar cell during the discharge process. ${ }^{\text {[24] }}$

As shown in Figure 5a, the $\eta_{\text {overall }}$ enhanced with the photo-charge time increasing, then the $\eta_{\text {overall }}$ reached a maximum and finally showed a downward trend slightly. The maximum $\eta_{\text {overall }}$ is $2 \%$ and the corresponding maximum $\eta_{\text {storage }}$ is $58 \%$, which is comparable with previous IPC devices based on metal common electrodes. ${ }^{[10,18]}$ Then cycle stability of the IPC is investigated 


\section{WILEY-VCH}

by photocharge and galvanostatic discharge at the current density of $1 \mathrm{~mA} \mathrm{~cm}^{-2}$ (Figure $5 \mathbf{b}$ ). The fact of the areal capacitance of the capacitor maintained almost the same after 100 cycles demonstrates the superior cycling stability of the IPC.

\section{Conclusions}

A novel lamination method assisted by hydrogen-bond interaction for free standing PEDOT:PSS electrodes has been developed, which is successfully applied to integrate a OSC and a capacitor to form a foldable IPC. Large area OSCs with free standing PEDOT:PSS as top electrode demonstrate comparable performance with that of Ag. Free standing capacitor based on the thick PEDOT:PSS electrode shows a high capacitance of $30 \mathrm{mF} \mathrm{cm}^{-2}$. The IPCs with free standing PEDOT:PSS as common electrodes exhibit comparable performance with those of IPCs based on metallic electrodes. Furthermore, the foldable IPC displays excellent charge/discharge cycling stability. This novel lamination method will greatly extend the applications of PEDOT:PSS electrode in other kinds of large area flexible organic electronic devices.

\section{Experimental Section}

\subsection{Preparation of PEDOT:PSS electrode}

The spin-coated PEDOT:PSS electrode is prepared by adding 5\% EG and 2\% PEG-TmDD into PH1000 solution and string for $1 \mathrm{~h}$. The detailed preparation procedures of the thick free standing PEDOT:PSS film is similar with our previous report. ${ }^{[17 b]}$ Firstly, the PH1000 solution was dropped into the diluted 0.5 M sulfuric acid solution for achieving PEDOT:PSS plates. Then these plates are collected and stirred for 24 hours for obtaining PEDOT:PSS paste. After that, $0.2 \%$ PEG-TmDD are added into the PEDOT:PSS paste to improve the wetting property of the free standing PEDOT:PSS film. The paste is fabricated into film by vacuum filtration. At last, a free standing PEDOT:PSS film is achieved after removing filter paper with acetone. 


\section{WILEY-VCH}

The film thickness depends on the volume and concentration of PEDOT:PSS paste (Note: in this work $1 \mathrm{~mL}$ paste corresponding to $0.667 \mathrm{~mL}$ ). The correlations between film thickness, sheet resistance and the volume of PEDOT:PSS paste were investigated (shown in Figure S8 and Table S4). The error bars of the thicknesses was displayed, which confirm the uniformity of the film.

\subsection{Fabrication of OSC}

The OSCs with a structure of ITO/PEI/P3HT:ICBA/PEDOT:PSS are fabricated as following: the ITO substrates are rinsed with detergent firstly, and then treated by TL-1 $\left(\mathrm{NH}_{3}: \mathrm{H}_{2} \mathrm{O}_{2}\right.$ : $\left.\mathrm{H}_{2} \mathrm{O}=1: 1: 5\right)$ procedure for $30 \mathrm{~min}$. PEI solution (0.1\%, isopropanol) is spin-coated on the cleaned ITO substrates at $4000 \mathrm{rpm}$ for $40 \mathrm{~s}$ followed by annealing at $120{ }^{\circ} \mathrm{C}$ for $15 \mathrm{~min}$. A solution consist of $20 \mathrm{mg}$ P3HT and $20 \mathrm{mg}$ ICBA in $1 \mathrm{~mL}$ of $o$-dichlorobenzene is spin-coated on the top of PEI at $700 \mathrm{rpm}$ for $60 \mathrm{~s}$ in glove box followed by annealing at $150{ }^{\circ} \mathrm{C}$ for $10 \mathrm{~min}$. Then the PEDOT:PSS solution is spin-coated onto the top of the photoactive layer at $800 \mathrm{rpm}$ for $60 \mathrm{~s}$ in atmosphere. Finally, the free standing PEDOT:PSS film is laminated onto the top of the device then dried in vacuum. The effective area of the device is around $1 \mathrm{~cm}^{2}$. The $J-V$ curves are measured using a Keithley 2400 under the irradiation of AM 1.5 G, $100 \mathrm{~mW} \mathrm{~cm}{ }^{-2}$.

\subsection{Fabrication of free standing capacitor}

The $\mathrm{H}_{3} \mathrm{PO}_{4}$-PVA electrolyte is prepared by dissolving PVA power (12 g) and $\mathrm{H}_{3} \mathrm{PO}_{4}$ (12 g) into $120 \mathrm{ml}$ water. The resulting mixture is heated to $85^{\circ} \mathrm{C}$ under stirring for $1 \mathrm{~h}$ until the clear electrolyte is obtained. Then the electrolyte is coated on the top of the free standing PEDOT:PSS electrode and dried in ventilation for $1 \mathrm{~h}$. the fabrication of capacitor is finished by sandwiching a $\mathrm{H}_{3} \mathrm{PO}_{4}-\mathrm{PVA}$ film between the electrodes as the separator.

\subsection{Fabrication of IPC}




\section{WILEY-VCH}

To fabricate IPC, OSCs with free standing PEDOT:PSS as top electrode (size is around $2.5 \times 1$ $\mathrm{cm})$ and the common electrode are fabricated. One side of the free standing PEDOT:PSS film is used as the electrode for the OSCs while the other side is used as the capacitor's electrode. Here, a polysulfones (PES) layer is introduced as the insulating layer between the two free standing PEDOT:PSS electrodes of the OSC and capacitor.

\subsection{Calculations}

The areal capacitances $\left(C_{\mathrm{A}}\right)$, energy density $\left(E_{\mathrm{Ca}}\right)$ and the power density $\left(P_{\mathrm{Ca}}\right)$ determined from the galvanostatic charge/discharge data are given by:

$$
\begin{aligned}
C_{\mathrm{A}} & =\frac{I \Delta t}{\Delta V A_{\mathrm{Ca}}} \\
E_{\mathrm{Ca}} & =0.5 C_{\mathrm{A}}(\Delta V)^{2} \\
P_{\mathrm{Ca}} & =\frac{E}{\Delta t}
\end{aligned}
$$

Where $I$ is the applied current, $\Delta t$ is the discharge time, $A_{\mathrm{Ca}}$ is the area of the capacitor $\left(A_{\mathrm{Ca}}=\right.$ $1 \mathrm{~cm}^{2}$ in this work), $\Delta V$ is the operating voltage obtained from the discharge profile excluding the voltage drop.

The $\eta_{\text {overall }}$ of the IPC is calculated from Equation (4) and the $\eta_{\text {storage }}$ is calculated from Equation (5).

$$
\begin{aligned}
& \eta_{\text {overall }}=E_{\mathrm{Ca}} \times A_{\mathrm{Ca}} / E_{\text {light }} \times A_{\mathrm{OSC}} \\
& \eta_{\text {storage }}=\eta_{\text {overall }} / P C E
\end{aligned}
$$

Where $E_{\text {light }}$ is incident light power density $\left(100 \mathrm{~mW} \mathrm{~cm}^{-2}\right)$ multiplied by the photocharge time, Aosc is the area of OSC (here is $1 \mathrm{~cm}^{2}$ ). 


\section{WILEY-VCH}

\section{Supporting Information}

Supporting Information is available from the Wiley Online Library or from the author

\section{Acknowledgements}

The work is supported by Vinnova Marie Curie incoming project (2016-04112), the Swedish

Government Strategic Research Area in Materials Science on Functional Materials at Linköping University (Faculty Grant SFO-Mat-LiU No 200900971) and China Scholarship Council (CSC).

Received: ((will be filled in by the editorial staff))

Revised: ((will be filled in by the editorial staff)) Published online: ((will be filled in by the editorial staff)) 


\section{WILEY-VCH}

\section{Reference}

[1] a) Y. Fu, H. Wu, S. Ye, X. Cai, X. Yu, S. Hou, H. Kafafy, D. Zou, Energy Environ. Sci. 2013, 6, 805; b) A. Takshi, H. Yaghoubi, T. Tevi, S. Bakhshi, J. Power Sources 2015, 275, 621; c) Y. Huang, M. Zhu, Y. Huang, Z. Pei, H. Li, Z. Wang, Q. Xue, C. Zhi, Adv. Mater. 2016, 28, 8344; d) H. Sun, Y. Zhang, J. Zhang, X. Sun, H. Peng, Nat. Rev. Mater. 2017, 2, 17023; e) R. Liu, Y. Liu, H. Zou, T. Song, B. Sun, Nano Res. 2017, 1; f) S. Pan, J. Ren, X. Fang, H. Peng, Adv. Energy Mater. 2015.

[2] T. Miyasaka, T. N. Murakami, Appl. Phys. Lett. 2004, 85, 3932.

[3] a) T. N. Murakami, N. Kawashima, T. Miyasaka, Chem. Commun. 2005, 3346; b) H.W. Chen, C.-Y. Hsu, J.-G. Chen, K.-M. Lee, C.-C. Wang, K.-C. Huang, K.-C. Ho, J. Power Sources 2010, 195, 6225; c) J. Bae, Y. J. Park, M. Lee, S. N. Cha, Y. J. Choi, C. S. Lee, J. M. Kim, Z. L. Wang, Adv. Mater. 2011, 23, 3446.

[4] G. Wee, T. Salim, Y. M. Lam, S. G. Mhaisalkar, M. Srinivasan, Energy Environ. Sci. 2011, 4, 413.

[5] C. Shi, H. Dong, R. Zhu, H. Li, Y. Sun, D. Xu, Q. Zhao, D. Yu, Nano Energy 2015, 13, 670.

[6] F. Zhou, Z. Ren, Y. Zhao, X. Shen, A. Wang, Y. Y. Li, C. Surya, Y. Chai, ACS Nano 2016, 10, 5900.

[7] Y. Sun, X. Yan, Solar RRL 2017, 1700002.

[8] Z. Zhang, X. Chen, P. Chen, G. Guan, L. Qiu, H. Lin, Z. Yang, W. Bai, Y. Luo, H. Peng, Adv. Mater. 2014, 26, 466.

[9] C.-T. Chien, P. Hiralal, D.-Y. Wang, I. S. Huang, C.-C. Chen, C.-W. Chen, G. A. J. Amaratunga, Small 2015, 11, 2929.

[10] J. Kim, S. M. Lee, Y.-H. Hwang, S. Lee, B. Park, J.-H. Jang, K. Lee, J. Mater. Chem. A 2017, 5, 1906. 


\section{WILEY-VCH}

[11] a) J. E. Yoo, K. S. Lee, A. Garcia, J. Tarver, E. D. Gomez, K. Baldwin, Y. Sun, H. Meng, T.-Q. Nguyen, Y.-L. Loo, Proc. Natl. Acad. Sci. U. S. A. 2010, 107, 5712; b) C. Xia, W. Chen, X. Wang, M. N. Hedhili, N. Wei, H. N. Alshareef, Adv. Energy Mater. 2015, 5, 1401805; c) C.-Y. Lu, C.-H. Tsai, Y.-T. Tsai, C.-J. Hsu, C.-H. Chang, C.-C. Wu, Adv. Energy Mater. 2015, 5, 1401738.

[12] a) Z. F. Li, Y. Liang, Z. C. Zhong, J. Y. Qian, G. J. Liang, K. Zhao, H. X. Shi, S. M. Zhong, Y. Z. Yin, W. J. Tian, Synth. Met. 2015, 210, 363; b) Z. F. Li, F. Qin, T. F. Liu, R. Ge, W. Meng, J. H. Tong, S. X. Xiong, Y. H. Zhou, Org. Electron. 2015, 21, 144; c) Z. Tang, Z. George, Z. Ma, J. Bergqvist, K. Tvingstedt, K. Vandewal, E. Wang, L. M. Andersson, M. R. Andersson, F. Zhang, O. Inganäs, Adv. Energy Mater. 2012, 2, 1467; d) X. Fan, J. Wang, H. Wang, X. Liu, H. Wang, ACS Appl. Mater. Interfaces 2015, 7, 16287; e) C. Yeon, S. J. Yun, J. Kim, J. W. Lim, Adv. Electron. Mater. 2015, 1, 1500121; f) Y. Wang, C. Zhu, R. Pfattner, H. Yan, L. Jin, S. Chen, F. Molina-Lopez, F. Lissel, J. Liu, N. I. Rabiah, Z. Chen, J. W. Chung, C. Linder, M. F. Toney, B. Murmann, Z. Bao, Sci. Adv. 2017, 3.

[13] a) G. Cai, P. Darmawan, M. Cui, J. Wang, J. Chen, S. Magdassi, P. S. Lee, Adv. Energy Mater. 2016, 6, 1501882; b) M. Zhang, Q. Zhou, J. Chen, X. Yu, L. Huang, Y. Li, C. Li, G. Shi, Energy Environ. Sci. 2016, 9, 2005; c) L. Fan, N. Zhang, K. Sun, Chem. Commun. 2014, 50, 6789.

[14] a) J. Ouyang, Y. Yang, Adv. Mater. 2006, 18, 2141; b) J. Huang, G. Li, Y. Yang, Adv. Mater. 2008, 20, 415; c) D. Gupta, M. M. Wienk, R. A. J. Janssen, Adv. Energy Mater. 2013, 3, 782; d) N. Kim, H. Kang, J. H. Lee, S. Kee, S. H. Lee, K. Lee, Adv. Mater. 2015, 27, 2317. 


\section{WILEY-VCH}

[15] a) Y. H. Kim, C. Sachse, M. L. Machala, C. May, L. Müller-Meskamp, K. Leo, Adv. Funct. Mater. 2011, 21, 1076; b) M. Vosgueritchian, D. J. Lipomi, Z. Bao, Adv. Funct. Mater. 2012, 22, 421.

[16] L. Mao, Q. Chen, Y. Li, Y. Li, J. Cai, W. Su, S. Bai, Y. Jin, C.-Q. Ma, Z. Cui, L. Chen, Nano Energy 2014, 10, 259.

[17] a) C. Liu, B. Lu, J. Yan, J. Xu, R. Yue, Z. Zhu, S. Zhou, X. Hu, Z. Zhang, P. Chen, Synth. Met. 2010, 160, 2481; b) Z. F. Li, G. Q. Ma, R. Ge, F. Qin, X. Y. Dong, W. Meng, T. F. Liu, J. H. Tong, F. Y. Jiang, Y. F. Zhou, K. Li, X. Min, K. F. Huo, Y. H. Zhou, Angew. Chem. Int. Ed. 2016, 55, 979.

[18] a) B. P. Lechêne, M. Cowell, A. Pierre, J. W. Evans, P. K. Wright, A. C. Arias, Nano Energy 2016, 26, 631; b) X. Xu, S. Li, H. Zhang, Y. Shen, S. M. Zakeeruddin, M. Graetzel, Y.-B. Cheng, M. Wang, ACS Nano 2015, 9, 1782.

[19] W. Ma, C. Yang, X. Gong, K. Lee, A. J. Heeger, Adv. Funct. Mater. 2005, 15, 1617.

[20] V. D. Mihailetchi, L. J. Koster, J. C. Hummelen, P. W. Blom, Phys. Rev. Lett. 2004, 93, 216601.

[21] Z. He, C. Zhong, X. Huang, W. Y. Wong, H. Wu, L. Chen, S. Su, Y. Cao, Adv. Mater. 2011, 23, 4636.

[22] N. Furukawa, H. Fujihara, Chem. Sulphonic Acids, Esters Their Deriv. 1991, 261.

[23] Z. F. Li, W. Meng, J. H. Tong, C. Zhao, F. Qin, F. Y. Jiang, S. X. Xiong, S. Zeng, L. Xu, B. Hu, Y. H. Zhou, Sol. Energy Mater. Sol. Cells 2015, 137, 311.

[24] J. Xu, Z. Ku, Y. Zhang, D. Chao, H. J. Fan, Adv. Mater. Technol. 2016, 1, 1600074. 


\section{WILEY-VCH}

Table 1 Photovoltaic performance of OSCs using three different types of top electrodes of spincoated PEDOT:PSS electrode (Cell-1), laminated PEDOT:PSS electrode (Cell-2) and silver electrode (Cell-3).

\begin{tabular}{cccccc}
\hline electrode & $\begin{array}{c}V_{\text {oc }} \\
(\mathrm{V})\end{array}$ & $\begin{array}{c}J_{\mathrm{sc}} \\
\left(\mathrm{mA} \mathrm{cm}^{-2}\right)\end{array}$ & $\begin{array}{c}\mathrm{FF} \\
(\%)\end{array}$ & $\begin{array}{c}\text { PCE } \\
(\%)\end{array}$ & $\begin{array}{c}R_{\mathrm{s}} \\
(\Omega)\end{array}$ \\
\hline Cell-1 & 0.85 & 5.93 & 0.43 & 2.17 & 46.7 \\
Cell-2 & 0.88 & 7.10 & 0.55 & 3.44 & 16.7 \\
Cell-3 & 0.83 & 8.11 & 0.57 & 3.84 & 5.54 \\
\hline
\end{tabular}




\section{WILEY-VCH}
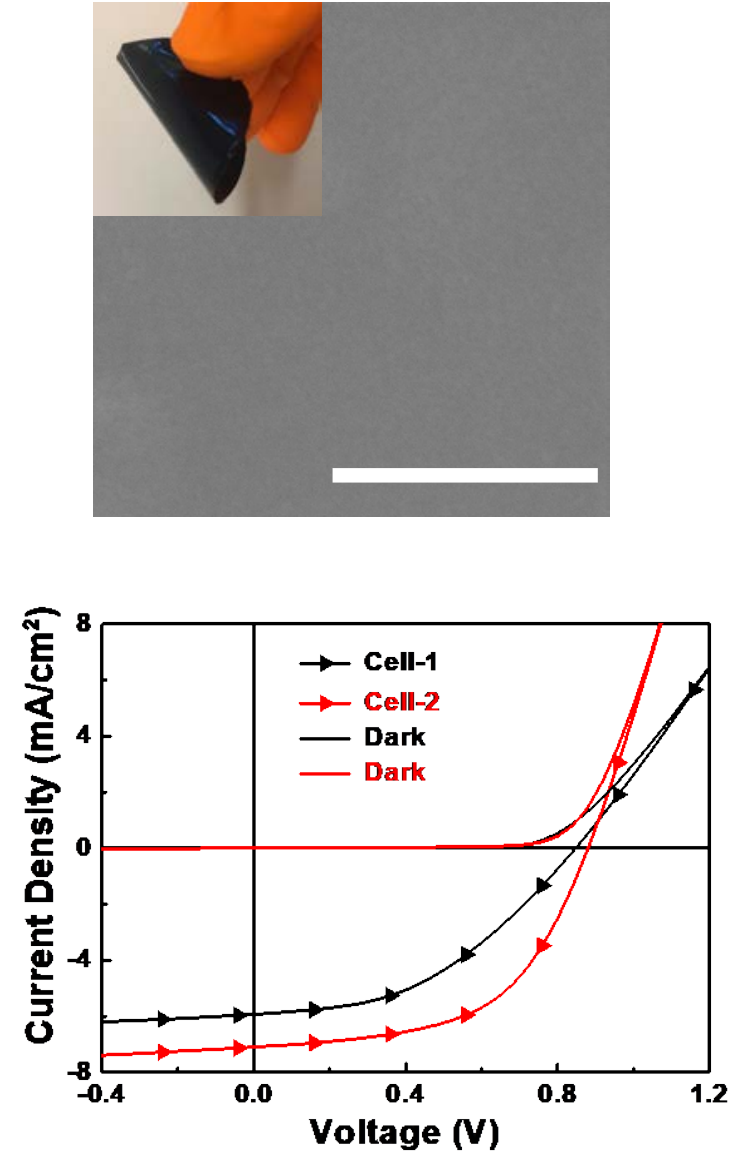

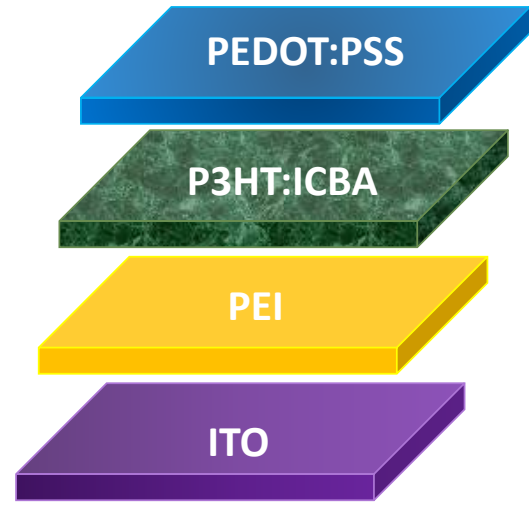

(d)

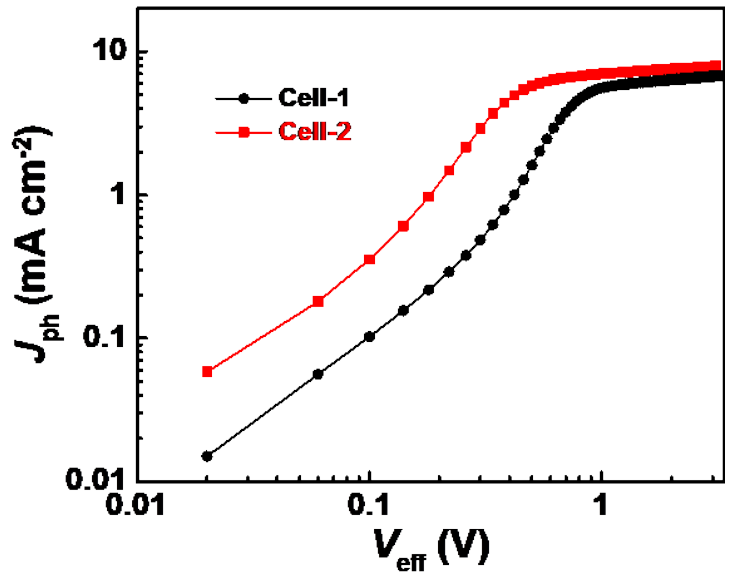

Figure 1. (a) SEM image of the free standing PEDOT:PSS film $(2 \times 2 \mu \mathrm{m})$ surface, inset is the photo-picture of the free standing PEDOT:PSS film. (b) Device structure based on spin-coated PEDOT:PSS electrode and laminated free standing PEDOT:PSS electrode. (c) $J$ - $V$ curves of Cell-1 and Cell-2, both the device areas are about $1 \mathrm{~cm}^{2}$. (d) $J_{\mathrm{ph}}-V_{\text {eff }}$ curves of OSCs based on different electrodes. 


\section{WILEY-VCH}
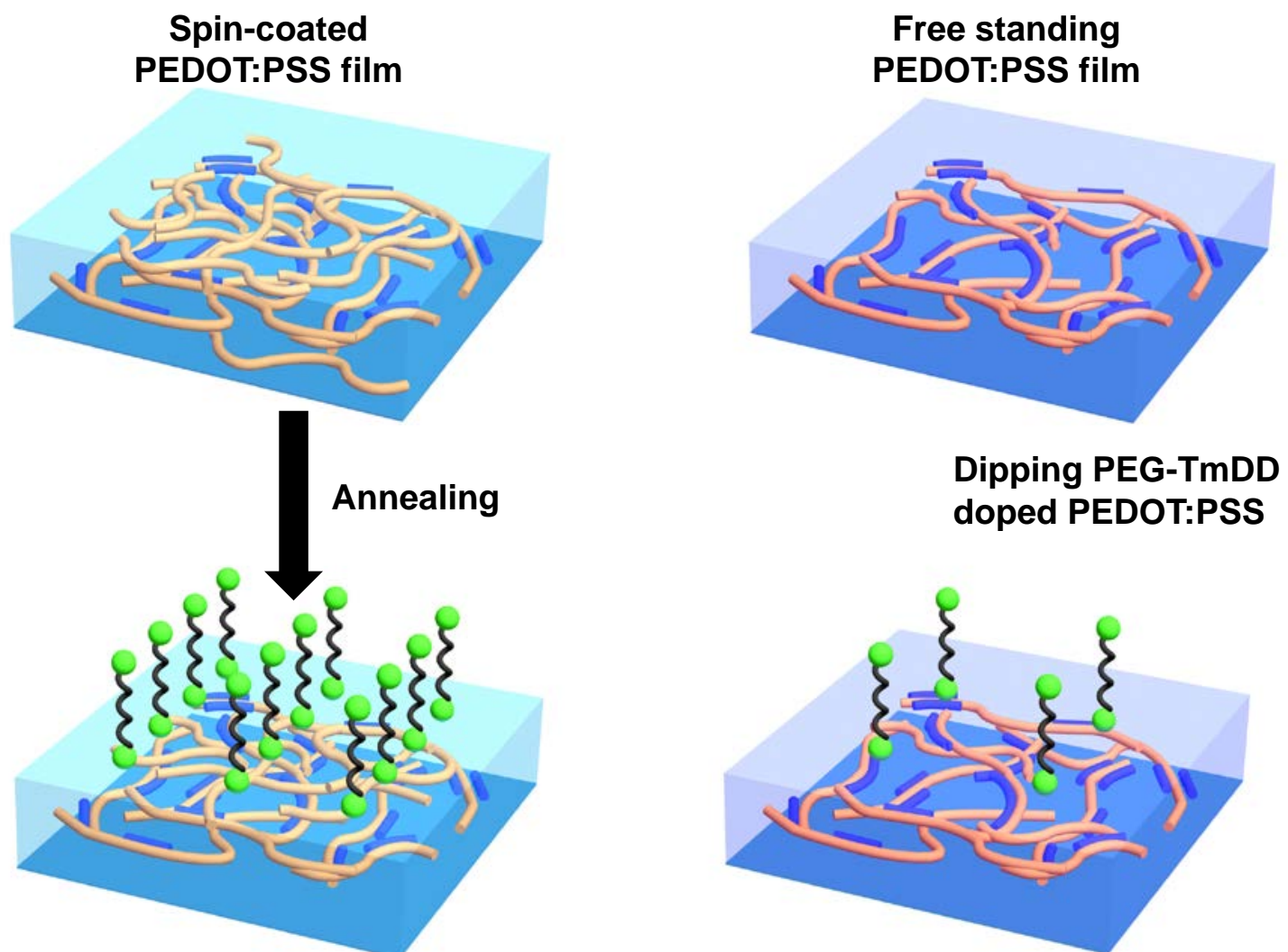

Dipping PEG-TmDD doped PEDOT:PSS
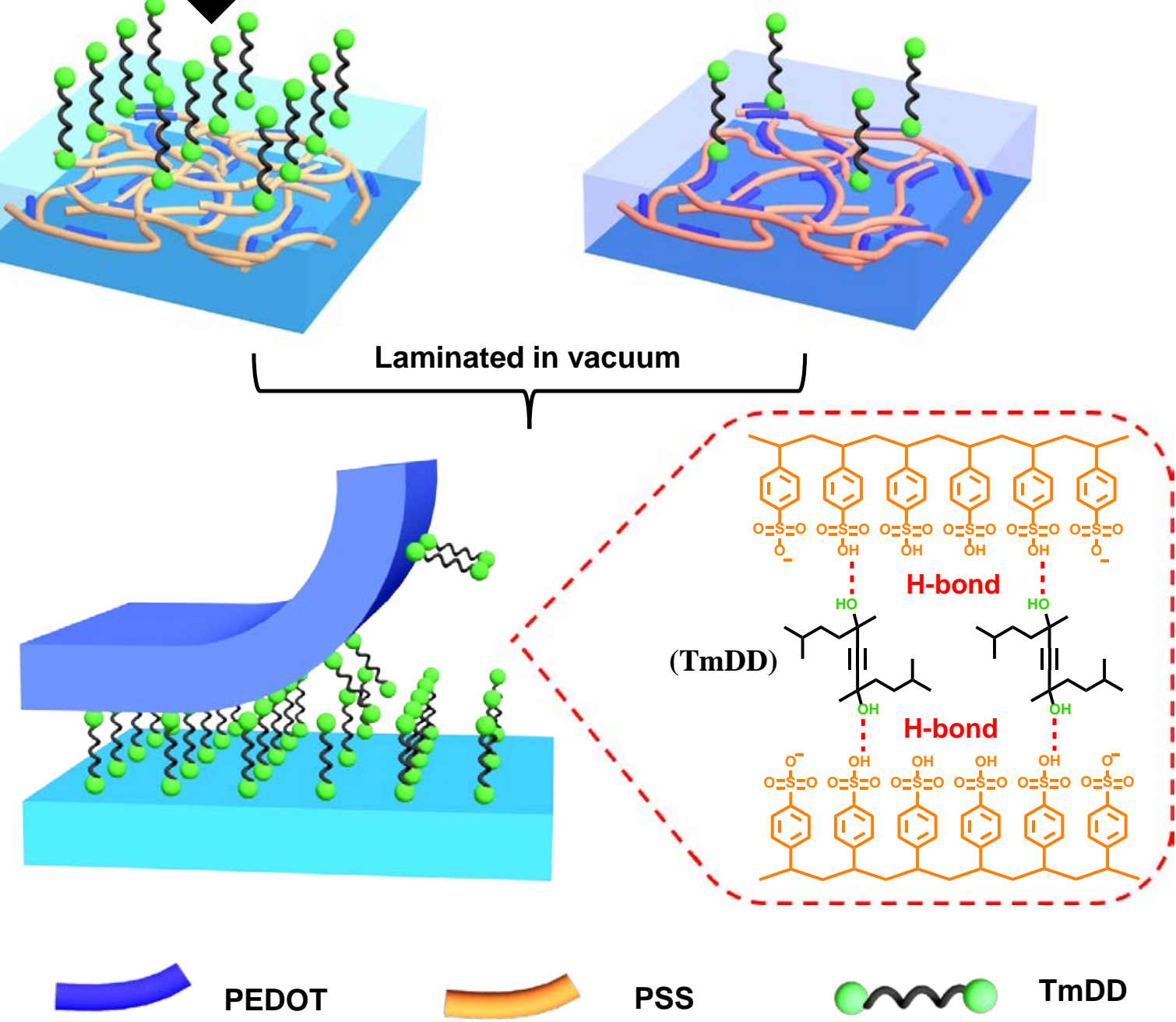

Figure 2. Schematic illustration of the free standing PEDOT:PSS electrode lamination method and corresponding mechanism. 


\section{WILEY-VCH}
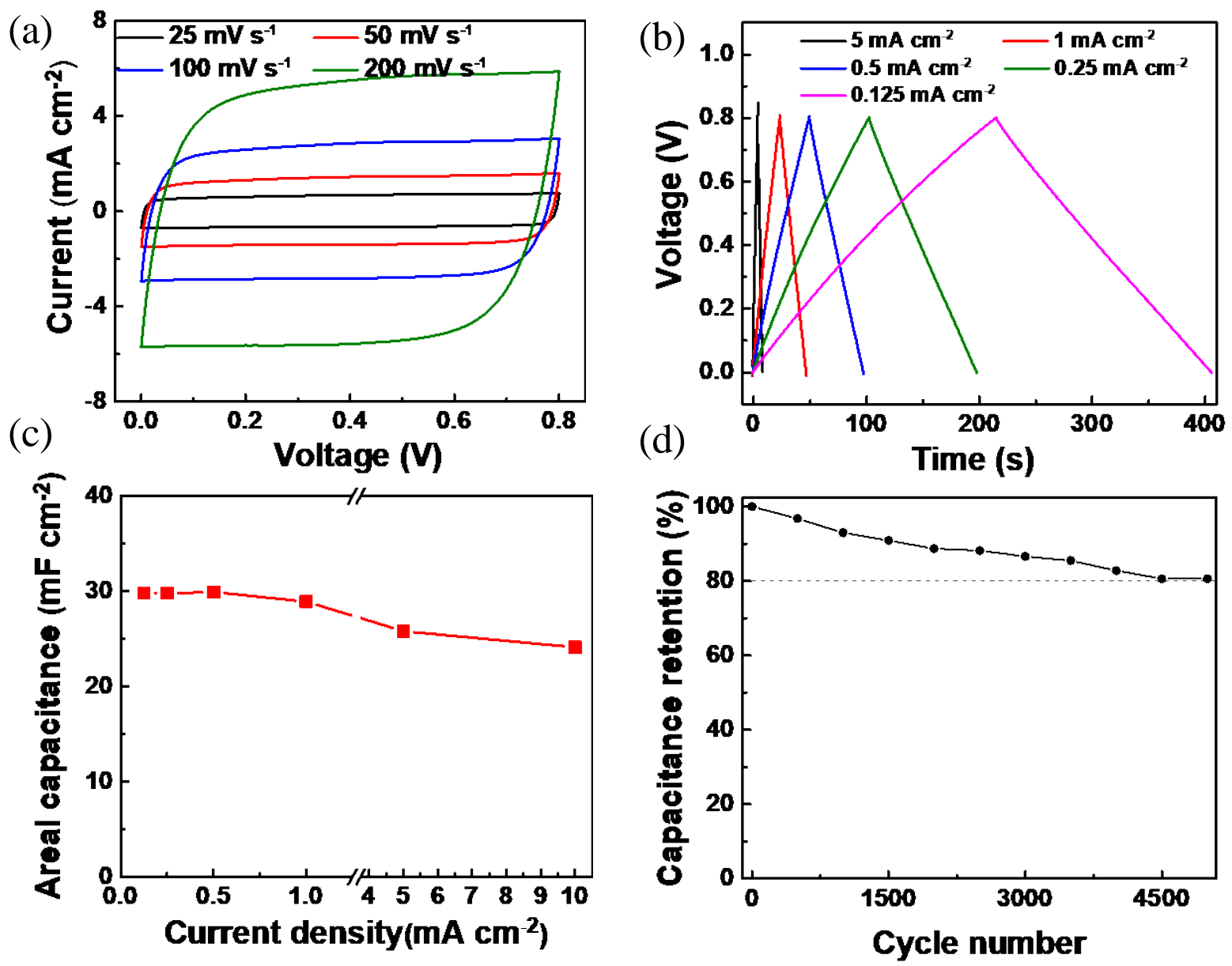

Figure 3. (a) CV curves of the capacitor recorded at different scan rate of 25, 50, 100 and 200 $\mathrm{mV} \mathrm{s}^{-1}$. (b) CD profiles of the capacitor recorded at different current density of $0.125,0.25,0.5$, 1 and $5 \mathrm{~mA} \mathrm{~cm}^{-2}$. (c) Specific areal capacitance as a function of current density. (d) Cycle stability of the solid-state capacitor with a CD current density of $1 \mathrm{~mA} \mathrm{~cm}{ }^{-2}$. 


\section{WILEY-VCH}

(a)

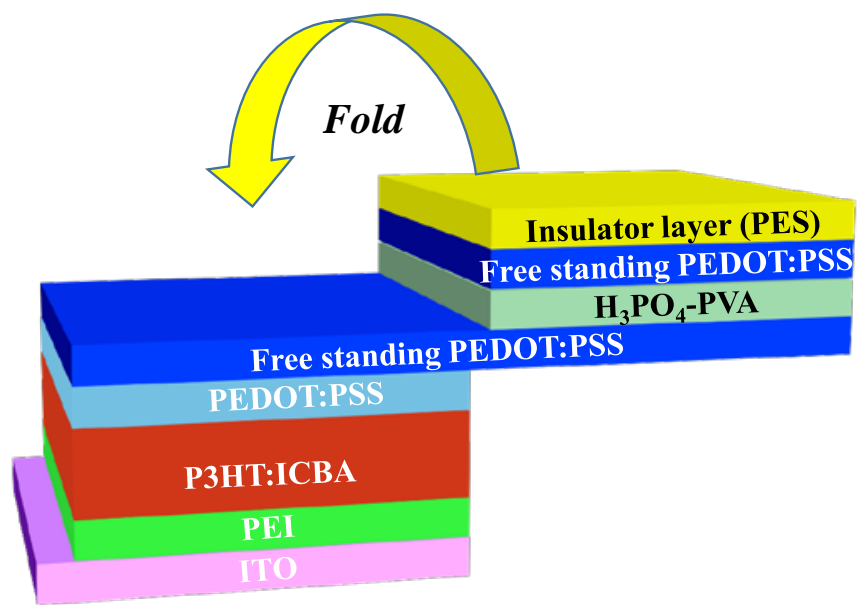

(b)

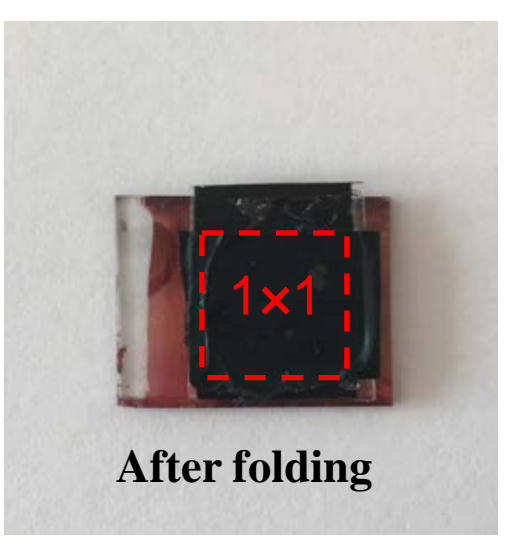

(c)

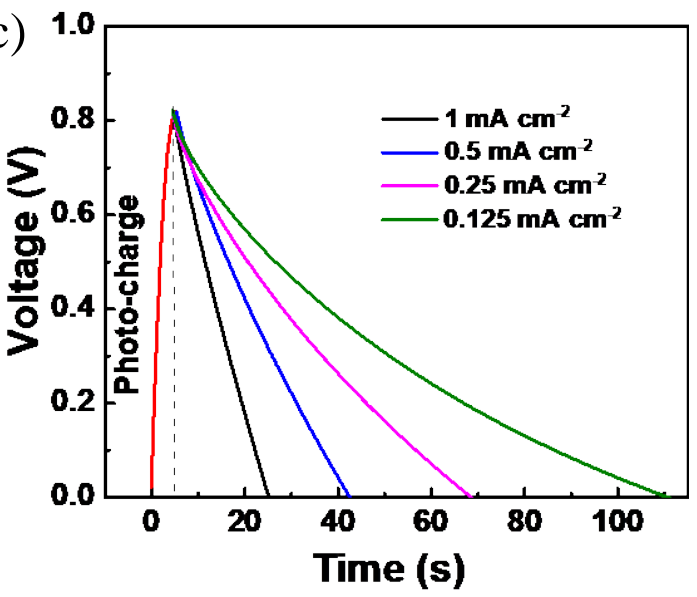

(d)

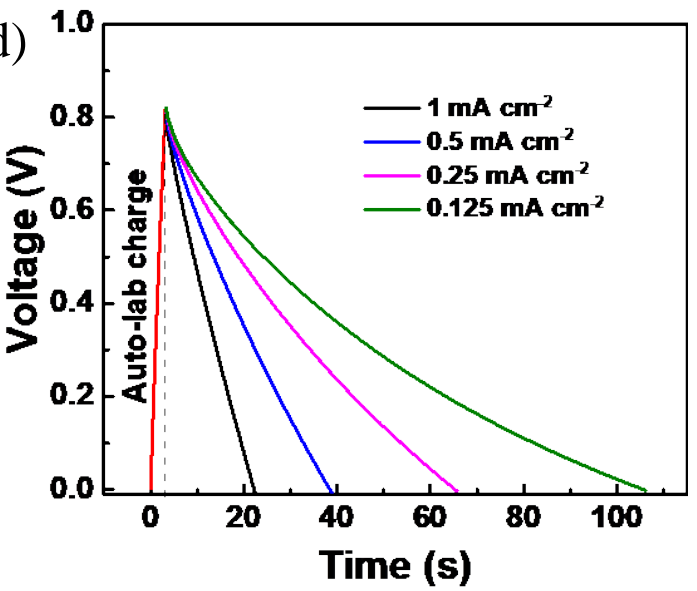

Figure 4. (a) Device structure of the foldable IPC. (b) Photo picture of the IPC under completely foldable condition (the active area of IPC is shown with the square). (c) The voltage transients of capacitor during photo-charge under AM 1.5 simulated sunlight $\left(100 \mathrm{~mW} \mathrm{~cm}^{-2}\right)$ illumination, and galvanostatic discharge at different discharge current densities in dark. (d) Capacitor performance with autolab-charge at the same charging current density of $7 \mathrm{~mA} \mathrm{~cm}^{-2}$. 
WILEY-VCH
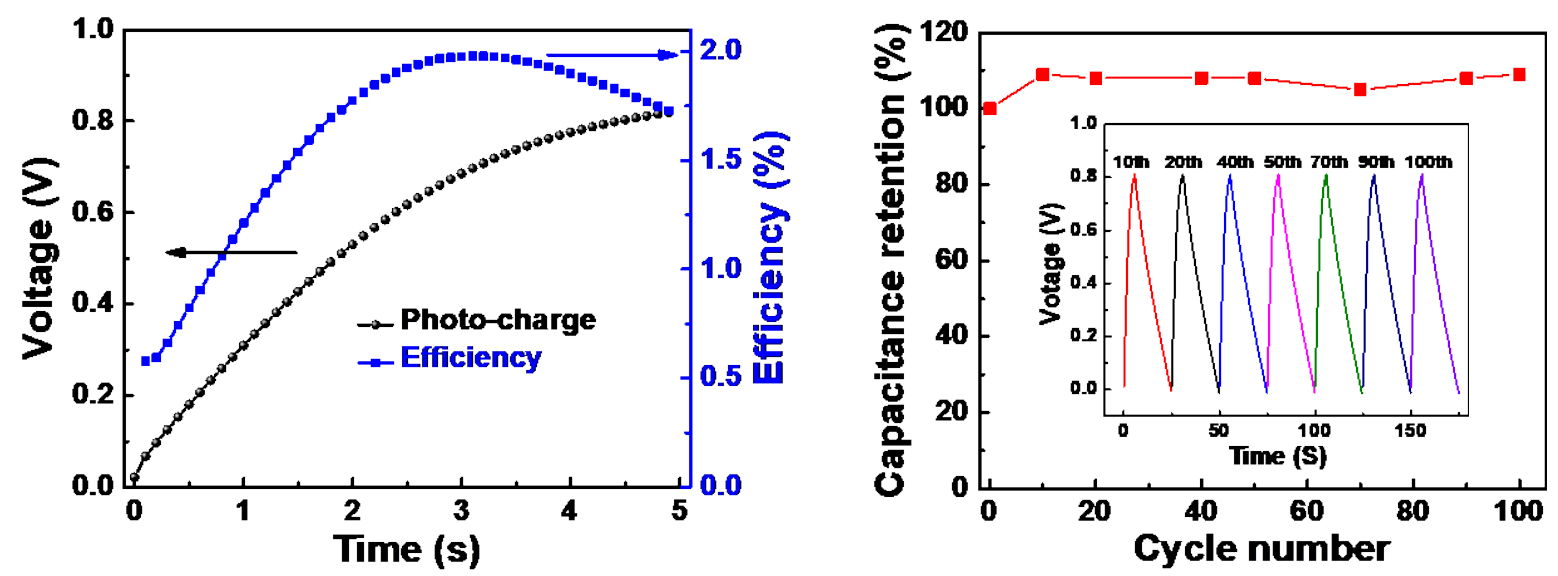

Figure 5. (a) The overall photoelectric conversion and storage efficiency of the IPC versus the photo-charge time. (b) Photo-charge/galvanostatic discharge cycle stability of the IPC at $1 \mathrm{~mA}$ $\mathrm{cm}^{-2}$ (inset shows the output voltage-time curves of 10, 20, 40, 50, 70, 80 and 100 cycles). 


\section{WILEY-VCH}

\section{The table of contents}

A novel lamination method for free standing PEDOT:PSS electrode has been developed and applied successfully onto large area metal-free organic solar cells and solution processed foldable IPCs assisted by hydrogen-bond interaction. This novel lamination method for PEDOT:PSS electrode will greatly extend applications of PEDOT:PSS electrode in other kinds of large area flexible organic electronics.

\section{Keyword}

Lamination method, Free standing PEDOT:PSS, Integrated photo-capacitor, Metal-free.

Yingzhi Jin, Zaifang Li*, Leiqiang Qin, Xianjie Liu, Lin Mao, Yazhong Wang, Fei Qin, Yanfeng Liu, Yinhua Zhou and Fengling Zhang*

\section{Title}

Laminated free standing PEDOT:PSS electrode for solution processed integrated photocapacitors via hydrogen-bond interaction

\section{ToC figure}

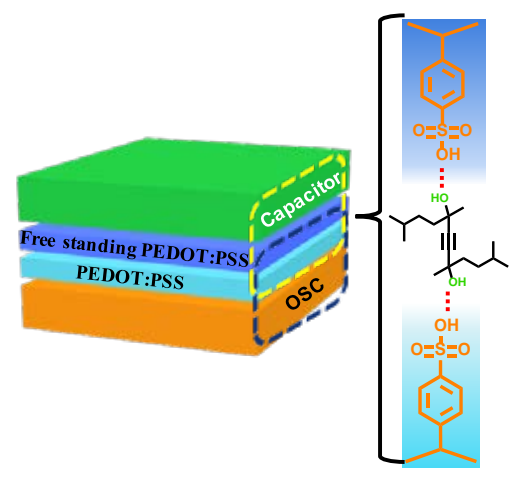




\section{WILEY-VCH}

Copyright WILEY-VCH Verlag GmbH \& Co. KGaA, 69469 Weinheim, Germany, 2016.

Supporting information

Laminated free standing PEDOT:PSS electrode for solution processed integrated photocapacitors via hydrogen-bond interaction

Yingzhi Jin, Zaifang Li*, Leiqiang Qin, Xianjie Liu, Lin Mao, Yazhong Wang, Fei Qin, Yanfeng Liu, Yinhua Zhou and Fengling Zhang*
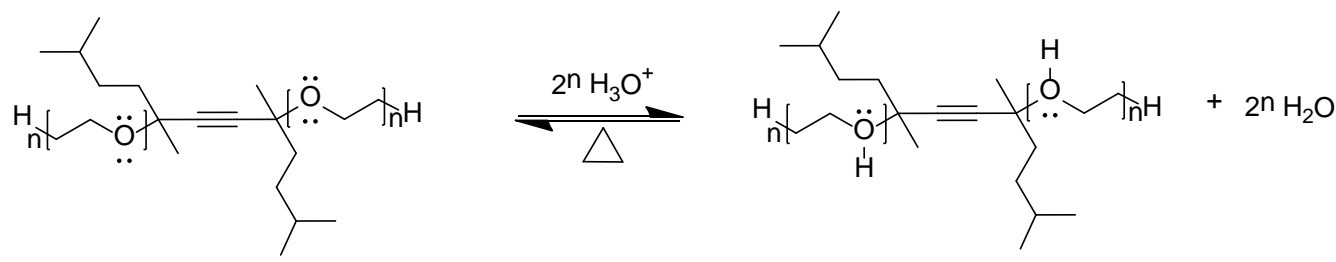

PEG-TmDD
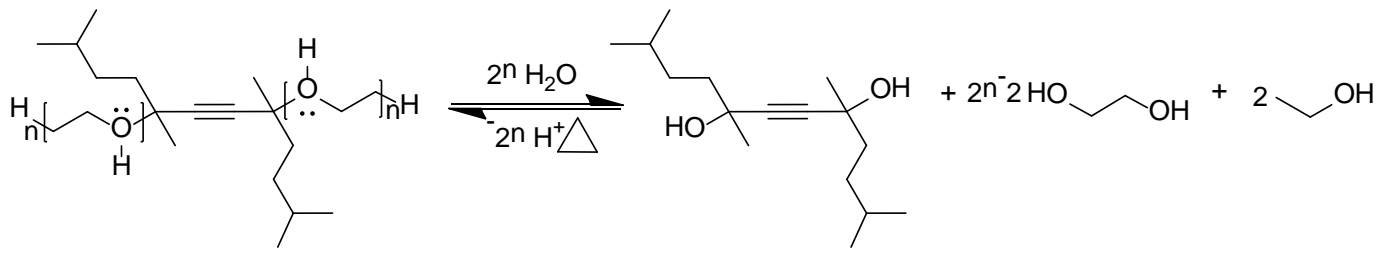

TmDD

Scheme S1. The decomposition route of PEG-TmDD under acid and heating conditions. 
Table S1 Thickness, $R_{\mathrm{sq}}$ and $\sigma$ of spin coated thin PEDOT:PSS electrode and laminated free standing PEDOT:PSS electrode.

\begin{tabular}{cccc}
\hline electrode & $\begin{array}{c}\text { Thickness } \\
(\mathrm{nm})\end{array}$ & $\begin{array}{c}R_{\mathrm{sq}} \\
\left(\Omega \mathrm{sq}^{-1}\right)\end{array}$ & $\begin{array}{c}\sigma \\
\left(\mathrm{S} \mathrm{cm}^{-1}\right)\end{array}$ \\
\hline $\begin{array}{c}\text { Spin coated } \\
\text { PEDOT:PSS }\end{array}$ & $226 \pm 7$ & $83.3 \pm 1.36$ & $531 \pm 21$ \\
$\begin{array}{c}\text { Free standing } \\
\text { PEDOT:PSS }\end{array}$ & $5790 \pm 230$ & $5.14 \pm 0.13$ & $336 \pm 17$ \\
\hline
\end{tabular}

Table S2. Data summarization of large area photovoltaic device with the structure of ITO/PEI/P3HT:ICBA/PEDOT:PSS/FS-PEDOT:PSS.

\begin{tabular}{ccccc}
\hline Area $\left(\mathrm{cm}^{2}\right)$ & $\begin{array}{c}V_{\mathrm{oc}} \\
(\mathrm{V})\end{array}$ & $\begin{array}{c}J_{\mathrm{sc}} \\
\left(\mathrm{mA} \mathrm{cm}^{-2}\right)\end{array}$ & $\begin{array}{c}\mathrm{FF} \\
(\%)\end{array}$ & $\begin{array}{c}\text { PCE } \\
(\%)\end{array}$ \\
\hline 1 & 0.88 & 7.10 & 0.55 & 3.44 \\
2.25 & 0.84 & 6.70 & 0.45 & 2.53 \\
\hline
\end{tabular}

Table S3. The device performance of OSCs based on different thickness free standing PEDOT:PSS film as top electrodes, the effective area of the active layer is $1 \mathrm{~cm}^{2}$. The average values for 3-5 devices.

\begin{tabular}{ccccc}
\hline $\begin{array}{c}\text { Free standing } \\
\text { film }\end{array}$ & $\begin{array}{c}V_{\mathrm{oc}} \\
(\mathrm{V})\end{array}$ & $\begin{array}{c}J_{\mathrm{sc}} \\
\left(\mathrm{mA} \mathrm{cm}^{-2}\right)\end{array}$ & $\begin{array}{c}\mathrm{FF} \\
(\%)\end{array}$ & $\begin{array}{c}\text { PCE } \\
(\%)\end{array}$ \\
\hline \multirow{2}{*}{$1.0 \mathrm{~mL}$} & 0.85 & 5.60 & 0.53 & 2.55 \\
& $(0.85 \pm 0.004)$ & $(5.59 \pm 0.11)$ & $(0.48 \pm 0.04)$ & $(2.27 \pm 0.26)$ \\
$1.5 \mathrm{~mL}$ & 0.88 & 7.10 & 0.55 & 3.44 \\
& $(0.87 \pm 0.01)$ & $(6.62 \pm 0.62)$ & $(0.53 \pm 0.02)$ & $(3.04 \pm 0.31)$ \\
$2.5 \mathrm{~mL}$ & 0.86 & 7.19 & 0.54 & 3.29 \\
& $(0.86 \pm 0.005)$ & $(6.41 \pm 0.55)$ & $(0.56 \pm 0.02)$ & $(3.05 \pm 0.17)$ \\
\hline \multicolumn{5}{c}{25} \\
\end{tabular}


Table S4. The summarized date of PEDOT:PSS paste volume, free standing PEDOT:PSS film thickness, $R_{\mathrm{sq}}$ and $\sigma$.

\begin{tabular}{cccc}
\hline Paste volume $(\mathrm{mL})$ & $\begin{array}{c}\text { Thickness } \\
(\mu \mathrm{m})\end{array}$ & $\begin{array}{c}R_{\mathrm{sq}} \\
\left(\Omega \mathrm{sq}^{-1}\right)\end{array}$ & $\begin{array}{c}\sigma \\
\left(\mathrm{S} \mathrm{cm}^{-1}\right)\end{array}$ \\
\hline $1.0 \mathrm{~mL}$ & $4.30 \pm 0.18$ & $6.43 \pm 0.62$ & $362 \pm 14$ \\
$1.5 \mathrm{~mL}$ & $5.79 \pm 0.23$ & $5.14 \pm 0.13$ & $336 \pm 17$ \\
$2.0 \mathrm{~mL}$ & $7.52 \pm 0.17$ & $4.03 \pm 0.57$ & $330 \pm 30$ \\
$2.5 \mathrm{~mL}$ & $10.8 \pm 0.66$ & $3.37 \pm 0.10$ & $275 \pm 4$ \\
$3.0 \mathrm{~mL}$ & $12.7 \pm 0.53$ & $2.91 \pm 0.24$ & $271 \pm 15$ \\
\hline
\end{tabular}



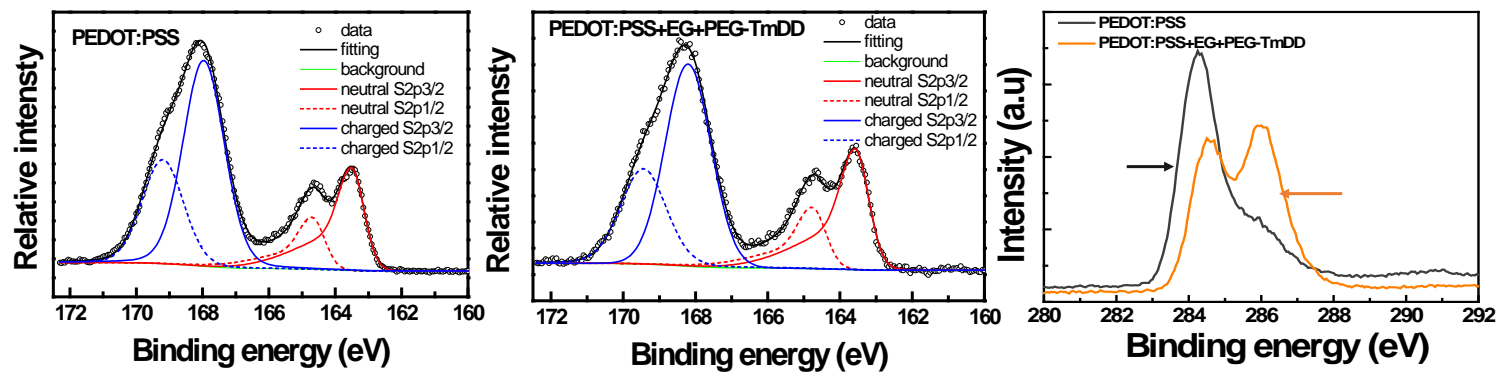

Figure S1. XPS characteristics of different PEDOT:PSS films. (a) Fitted curves of pristine PEDOT:PSS film for sulphur atoms, (b) Fitted curves of 5\% EG and 2\% PEG-TmDD treated PEDOT:PSS film for sulphur atoms, (c) Curves for carbon atoms of both pristine PEDOT:PSS film and with 5\% EG and 2\% PEG-TmDD treated PEDOT:PSS film.

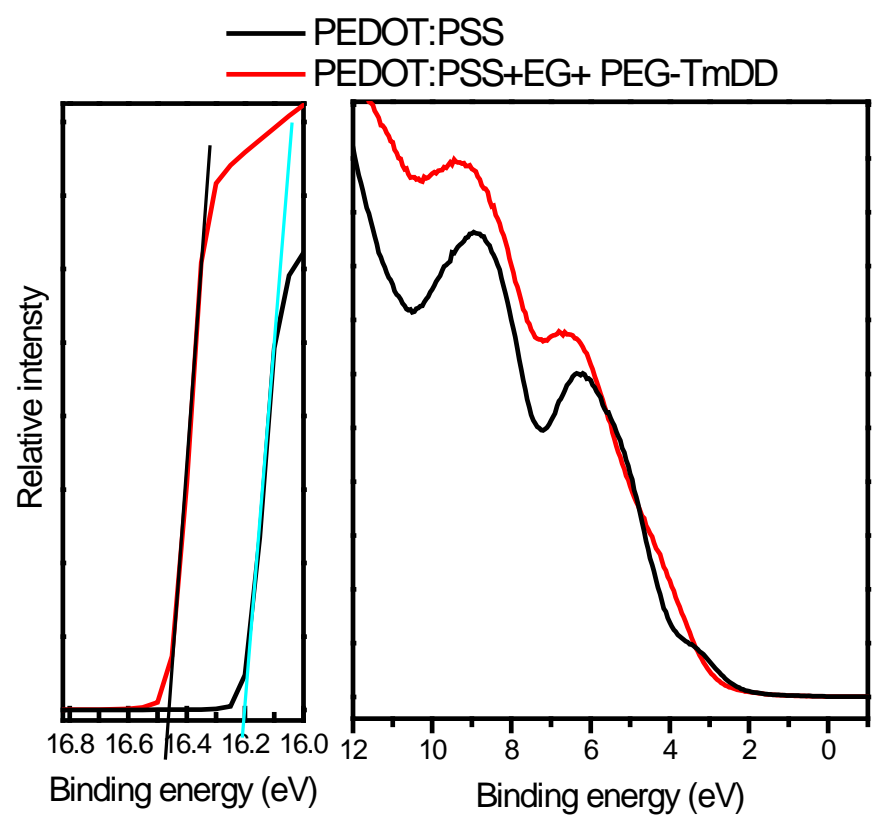

Figure S2. UPS measurement of pristine PEDOT:PSS and PEDOT:PSS doped with 5\% EG and 2\% PEG-TmDD. 


\section{WILEY-VCH}

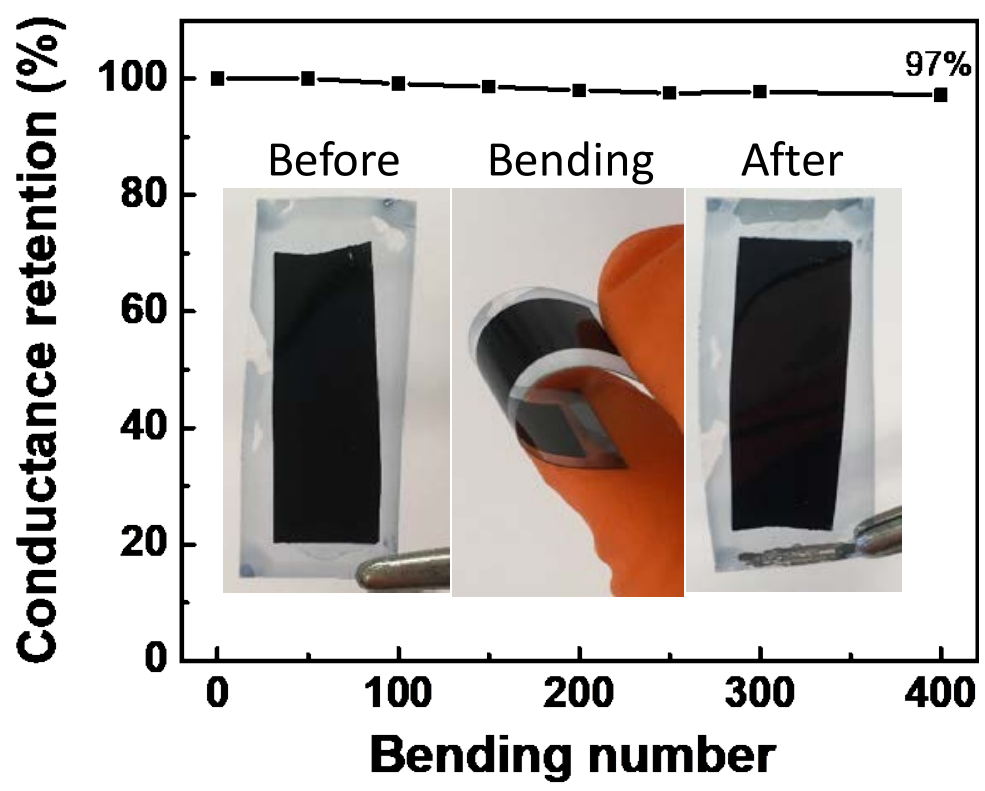

Figure S3. The conductance of a laminated PEDOT:PSS layer under bending. The photos (Inset) are images of the layer before bending, bending and after 400 bending.

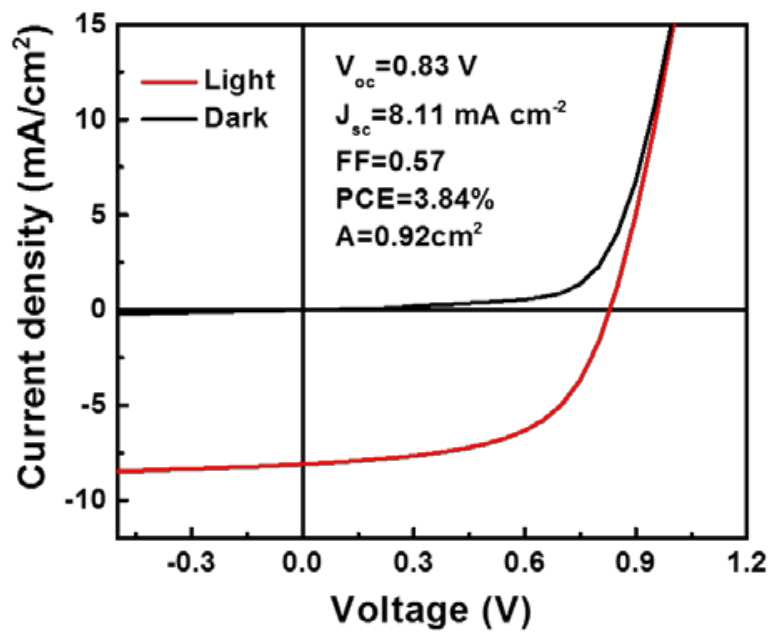

Figure S4. $J-V$ curves of the large area organic solar cells with device structure of ITO/PEI/P3HT:ICBA/MoO3/Ag. 


\section{WILEY-VCH}

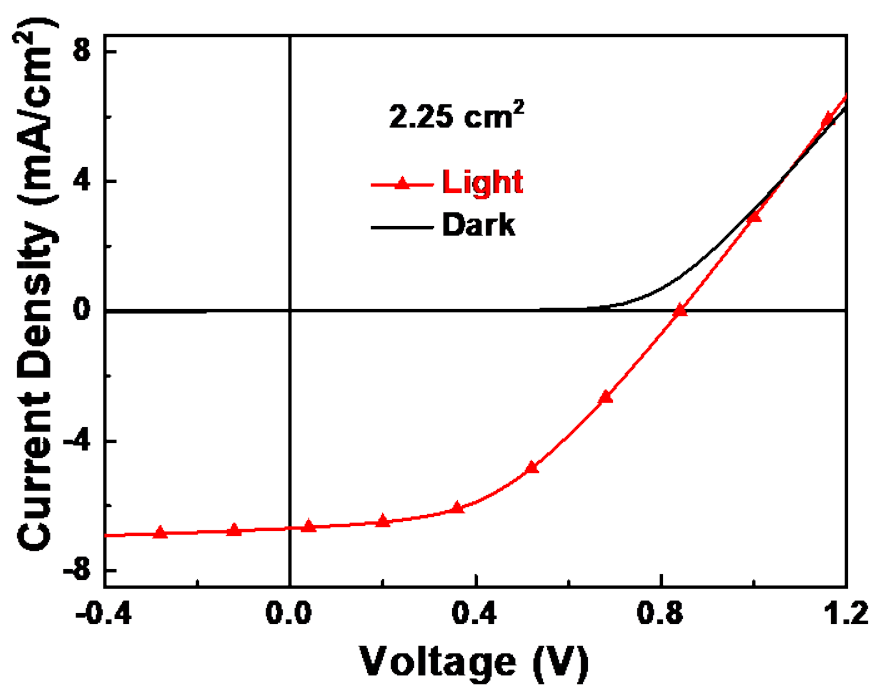

Figure S5. J-V curves of photovoltaic device with the structure of ITO/PEI/P3HT:ICBA/PEDOT:PSS/FS-PEDOT:PSS in dark and under AM 1.5 sun light with an effective large area of $2.25 \mathrm{~cm}^{2}$.

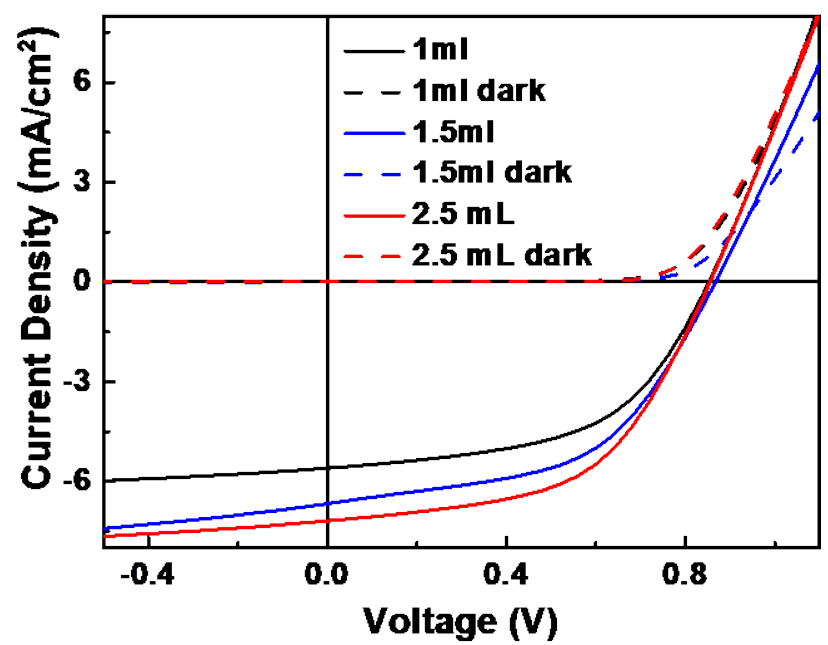

Figure S6. The relationship between free standing PEDOT:PSS film thickness and photovoltaic device performance. 


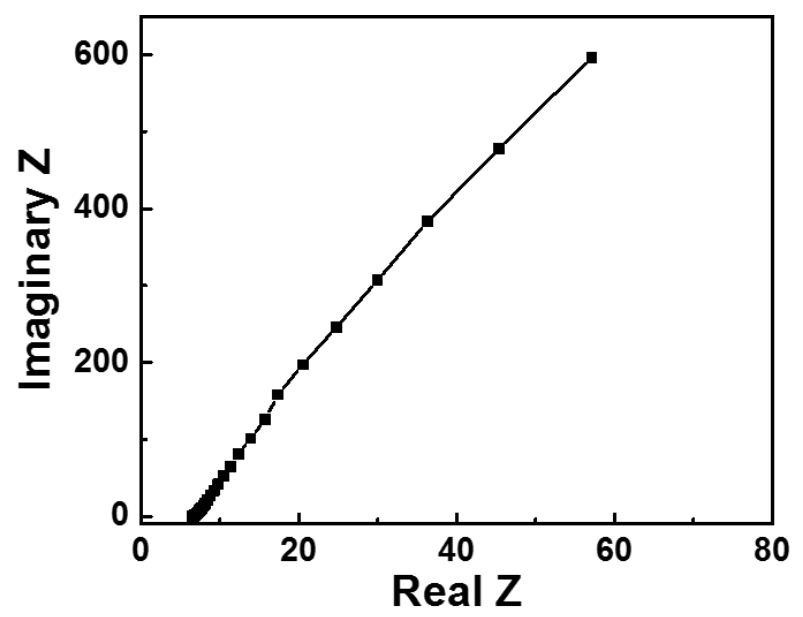

Figure S7. Impedance measurement of the capacitor.

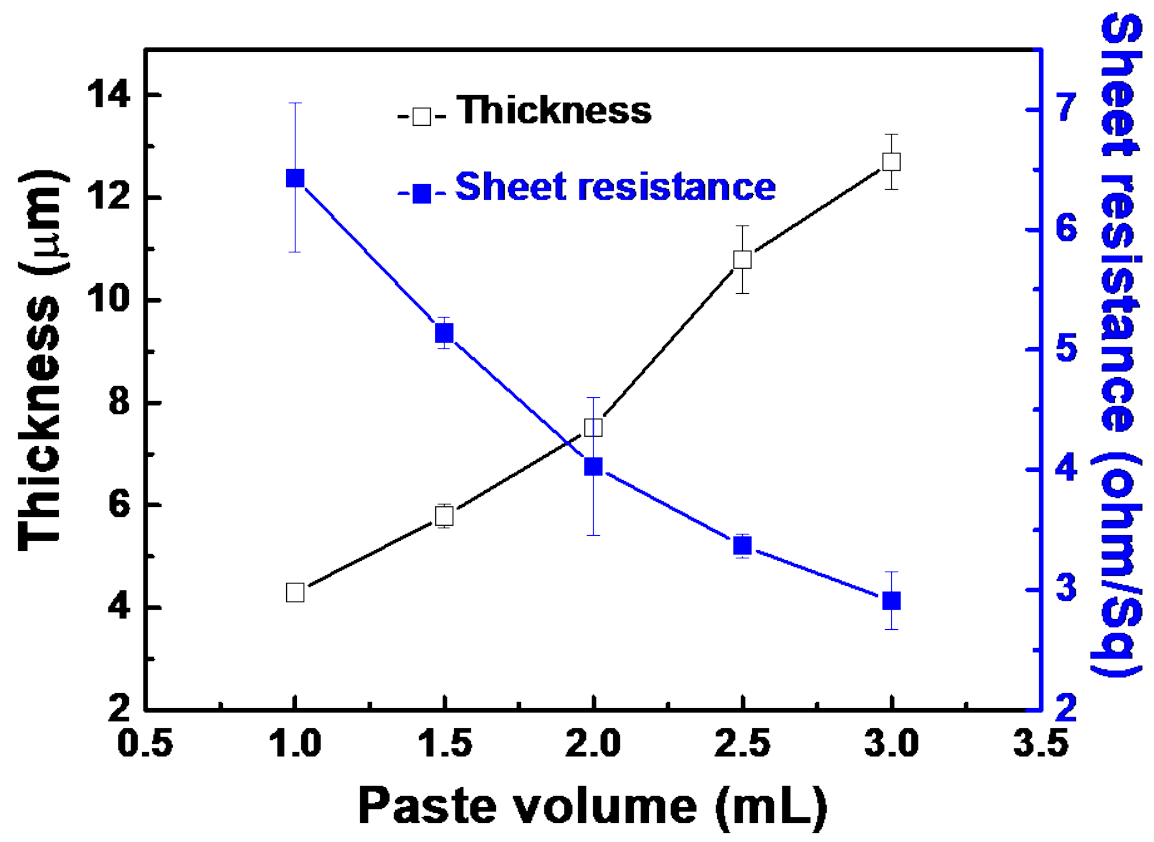

Figure S8. Relationship between PEDOT:PSS paste volume, free standing PEDOT:PSS film thickness and sheet resistance. 